\title{
Oral health and oral health risk behaviour in children with and without externalising behaviour problems
}

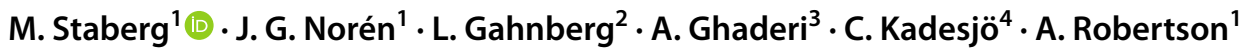

Received: 19 July 2017 / Accepted: 16 April 2018 / Published online: 15 May 2018

(c) The Author(s) 2018

\begin{abstract}
Aim This was to study children with early detected externalising behaviour problems compared to matched controls regarding oral health, oral health risk behaviour and the parental evaluation of the child's oral health and dental care.

Methods Children aged 10-13 years and with externalising behaviour problems, were compared to matched controls. Behavioural characteristics were based on the Strength and Difficulties Questionnaire. The children and their parents completed questionnaires regarding dental fear, tooth brushing, dietary habits and evaluation of oral health and dental care. Data on dental caries risk assessments, caries, behaviour management problems and dental trauma were obtained from dental files. Results There were no differences in caries prevalence in children with early detected externalising behaviour problems, compared to controls. However, the former group consumed more sweet drinks when thirsty and brushed their teeth fewer than twice daily; they also had more dental trauma in both dentitions and a higher risk range for dental fear, compared to controls. Conclusions This study points out potential oral health risk factors in children with early-detected externalising behaviour problems. Although no difference in caries prevalence was observed, externalising behaviour may affect oral health. Therefore, dental professionals should support the families and the children to preserve dental health by offering increased prophylactic measures. There were no differences between children with externalising behaviour problems, compared with controls, regarding the parent evaluation of their child's dental health. However, more parents in the study group evaluated the dental care as poor or not functioning.
\end{abstract}

Keywords Child behaviour $\cdot$ Conduct problems $\cdot$ Dental caries $\cdot$ Dental fear $\cdot$ Dental trauma $\cdot$ Disruptive behaviour disorder

\section{Introduction}

A considerable number of children and adolescents suffer from emotional and behavioural problems. According to a British review the prevalence of having signs of significant

M. Staberg

marie.staberg@vgregion.se

1 Department of Pediatric Dentistry, Institute of Odontology, The Sahlgrenska Academy, University of Gothenburg, P.O. Box 450, 40530 Gothenburg, Sweden

2 Department of Behavioral and Community Dentistry, Institute of Odontology, The Sahlgrenska Academy, University of Gothenburg, Gothenburg, Sweden

3 Department of Clinical Neuroscience, Karolinska Institutet, Stockholm, Sweden

4 Gillberg Neuropsychiatry Centre, Institute of Neuroscience and Physiology, The Sahlgrenska Academy, University of Gothenburg, Gothenburg, Sweden problem behaviour is between 10 and $20 \%$ in children and adolescents (Ogundele 2018). Childhood behaviour problems, such as hostile aggression and hyperactivity, are undesired due to norms of conventional society and defined as behaviour that is socially a problem. Externalising behaviour problems (EBP) include attention deficit hyperactivity disorder (ADHD) problems (inattention, hyperactivity/impulsivity), as well as disruptive, oppositional, aggressive, and conduct disorder behaviour (Bloomquist and Schnell 2002).

Externalising behaviour in children has been shown to influence both dental care and oral health (Staberg et al. $2014 a, b)$. An oral health risk behaviour can be expressed as a child brushing its teeth less than twice a day, and consuming more sweets and sweetened drinks several times a day.

Therefore, it is important to establish good routines in childhood, to promote and improve oral health. Good oral health habits can continue throughout adulthood, giving 
a lifelong protection from dental diseases (Loe 2000; Aunger 2007).

In children with ADHD, the frequent consumption of sugar can be difficult for the parents to deal with, and sometimes, the oral hygiene/tooth brushing is neglected (Staberg et al. 2014b). Among children with externalising behaviour problems, those with an elevated caries risk have been shown to have more impulsivity and conduct problems, compared to children with low caries risk (Staberg et al. 2016).

Children with traumatic dental injuries (TDI) have more hyperactive symptoms than children without dental trauma (Herguner et al. 2015). The frequency of dental injuries in children with ADHD peaks at the age of 10-12 years, with the main causes of dental injuries being falls, collisions with objects, violence and traffic accidents (Avsar et al. 2009).

A Swedish review article has found a relationship between dental fear and children with externalising problems (Klingberg and Broberg 2007). Dental anxiety and behaviour management problems are higher in children with ODD/ ADHD, than in children without ODD/ADHD (Aminabadi et al. 2016), and may delay or prevent dental treatment.

All children in Sweden are assessed for caries risk at their regular dental examinations, with the outcome used for caries preventive planning for those children who need it the most (Twetman et al. 2013). Therefore, it is important to evaluate if, and in what way, oral health differs between children with early-detected externalising problems, and matched controls. In cases where it is indicated, this information can be used to design and implement early, effective interventions and provide active help for children with externalising problems, and their parents.

The aim of the present paper was to study children with early-detected externalising behaviour problems, compared to matched controls, regarding oral health, oral health risk behaviour and the parent's evaluation of the child's oral health and dental care.

\section{Hypothesis}

Children with externalising behaviour problems have a risk behaviour influencing caries, dental trauma, dental fear, and poorer oral health routines (e.g., less frequent tooth brushing habits and more frequent cariogenic dietary habits compared to controls).

\section{Subjects and methods}

\section{Study group}

The study group was comprised of 194 families with children (10-13 years of age), whose parents participated in parent management training (PMT) programs, evaluating early intervention for children with externalising behaviour problems, previously described in detail (Staberg et al. 2016).

Briefly, 796 families, who experienced some degree of externalising behaviour problem with their child (e.g., parents with children in conflict with peers, parents or other adults, protesting against demands, often restless, having friends with bad influence or having been involved in vandalism, shoplifting or truancy) responded to advertisements about participating in the study. After obtaining written informed consent, the parents were asked to fill out the Strengths and Difficulties Questionnaire (SDQ) (Goodman 1997). Children below the cut-off point, the criteria for clinically relevant problems (less than three points on the conduct problem subscale of the SDQ), and children with autism, obsessive compulsive disorder or ongoing psychiatric treatment, were excluded. Finally, 231 families entered the study; 3 children were excluded due to missing dental records, and 34 children were excluded due to missing questionnaire and/or dental data, resulting in a total number of 194 children (113 boys, 81 girls). A flow chart illustrating the recruitment process and dropouts is presented in Fig. 1.

\section{Control group}

For each child in the study group, three possible matched controls, with the same age, gender, dental clinic and socioeconomic area (residential address), were identified. The first one, of the three matched controls, accepting the invitation was selected. It was possible to recruit 194 children into the study group and 153 into the control group (63 girls and 90 boys). All parents were asked to fill out the same questionnaire (SDQ) as the study group. Children with a value $\geq 3$ or more on the conduct problem subscale of the SDQ, (six girls, eight boys), were excluded to ensure a control group without externalising behaviour problems, resulting in 139 controls (57 girls, 82 boys) (Fig. 1).

\section{Instruments}

\section{Background information questionnaires}

The parents were asked to provide background information through a questionnaire, regarding dental care and the 
Fig. 1 Flow chart describing the recruitement of patients to the study group and to the control group, respectively. $S D Q$ Strengths and Difficulties Questionnaire, $S D Q-C D$ Strengths and Difficulties Questionnaire conduct problems

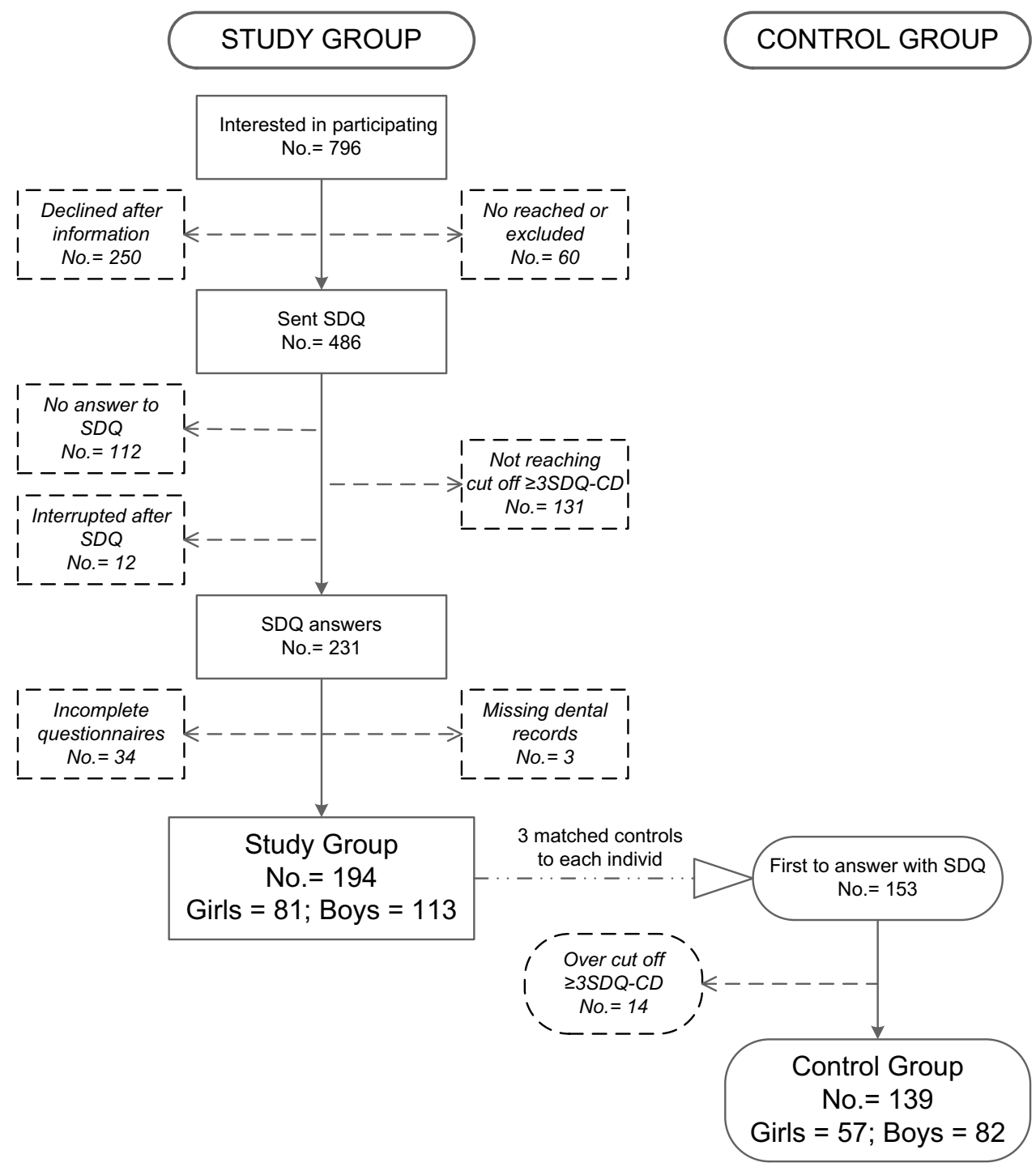

parent's evaluation of their child's oral health. The child responded to a questionnaire regarding dental fear, tooth brushing frequency, and dietary habits.

\section{The Strengths and Difficulties Questionnaire (SDQ)}

The Strengths and Difficulties Questionnaire (Goodman 1997 ) is a frequently used screening instrument for child and adolescent mental health, throughout the world, with good psychometric properties (Goodman 2001). The parental version of the SDQ for children 4-16 years, used in this study, can be completed within a few minutes and is validated for Swedish conditions (Smedje et al. 1999).

The SDQ symptom scales contain 25 items divided into five subscales, namely, Emotional Symptoms, Conduct Problems, Hyperactivity-Inattention, Peer Problems, and Prosocial Behaviour. A 3-point Likert scale is employed to indicate how each attribute applies to the target child $(0=$ not true; $1=$ somewhat true; $2=$ certainly true). All subscales, with the exception of prosocial behaviour, are summed together to a total difficulties score. A high score on the Prosocial Behaviour subscale indicates a strength, while high scores on the other four subscales indicate difficulties.

\section{Dental fear (CFSS-DS)}

The Dental Subscale of the Children's Fear Survey Schedule (CFSS-DS) is a well-known instrument for assessing dental fear in children, initially presented by Cuthbert and Melamed (1982). The CFSS-DS consists of 15 items, related to various aspects of dental treatment. Each item can be scored on a 5-point scale from 1 (not afraid) to 5 (very afraid). Total scores range from 15 to 75 .

The cut-off score of 38 or higher on the CFSS-DS has been commonly used to define dental fear, irrespective of age, gender, and informant. In the present study, the cut-off 
score was set to $\geq 32$ points, indicating "borderline" or "risk for dental fear", which has been used in previous studies (ten Berge et al. 2002; Fagerstad et al. 2015). Some children have no, or very limited, experience of invasive dental treatment and are therefore unable to answer all 15 questions in the survey on the CFSS-DS. Where responses to one or a maximum of three survey questions were missing then an average score was calculated. That score was used, thereby, so that a total of CFSS-DS could still be established.

\section{Dental records}

Data from dental records regarding caries in the primary teeth (deft, 12 teeth canine, first and second primary molars), caries in the permanent teeth (DMFT) and initial caries in first permanent molars, were compiled. Since children are growing individuals with different dental stages, ages, and number of teeth, caries in the first permanent molar was chosen as an expression for the caries situation.

All Swedish children are assessed for caries risk at their dental examinations. Data regarding caries risk was compiled from the dental file system used, by the Public Dental Service in the Region of Västra Götaland. The caries risk assessment is set by a combination of the computerised algorithm-based system R2 (Andas and Hakeberg 2014), and a clinical assessment made by each child's regular dentist, according to regional standardised guidelines by the Region of Västra Götaland. Those guidelines can be obtained by contacting the corresponding author.

The caries activity, based on new caries lesions and caries progression, is estimated in combination with modifying factors such as diet, fluoride, oral hygiene, previous caries experience, age, and medical risk recorded. The R2 system finally defines the caries risk as low, intermediate, or high. In order to identify children at risk, the caries risk data were dichotomised to low and elevated caries risk. The intermediate and high caries risk group together, formed the elevated caries risk group.

Data regarding dental trauma in the primary and permanent teeth, behaviour management problems (BMP), defined as notes in the dental records, clearly expressing severe disruptive behaviours, were also collected from dental files. In this study all dental files have been reviewed and read through from the very first dental visit.

\section{Statistical analysis}

Statistical analysis was performed using the statistical software R (GNU General Public License, Free Software Foundation, Inc., Boston, USA) and the Statistical Package for Social Sciences (SPSS version 21). Bonferroni-Holm corrected p-values were calculated by the multitest procedure in SAS Version 9.3 (SAS institute. Ink, Cary, NC, USA).

A logistic regression was used to assess the association between children with externalising behaviour problems and dental caries, traumatic dental injuries, oral health risk factors, dental fear and parental evaluation of dental care, and the child's oral health, compared to controls. Data were adjusted for age and gender. The results were expressed as odds ratio (OR) with a 95\% confidence interval. For multiple interferences, the significance level was adjusted according to the Bonferroni-Holm method and in the results, both unadjusted and adjusted values are presented.

\section{Ethical considerations}

The study was approved by the Ethical Committee in Uppsala (dnr 2010/119). All families participating in the project were given written information. Written consent from the participating families was received, in order to acquire access to their child's dental records.

\section{Results}

In order to make the presentation of the results more explicit, the results are shown in four different tables, including unadjusted and adjusted p-values.

\section{Study group vs. control group}

\section{Gender and year of birth}

The distribution of age and gender in the study group and the control group were approximately similar. The mean age in the study group was 11.7 years (SD 1.6) and the corresponding values in the control group were 11.6 years (SD 1.7).

\section{Caries and caries risk assessment (R2)}

\section{Caries}

No statistical significant difference was found regarding caries in the primary and permanent teeth, and caries in the primary and/or permanent dentition, and number of decayed, missing/filled first permanent molars, including initial caries between the two groups.

Upon entering the study, $28.9 \%$ of the children in the study group had filled or decayed first permanent molars, compared to $18.7 \%$ of the controls. The difference was statistically significant in the logistic regression analysis 
Table 1 The upper part of the table shows the number of children with primary dental caries and permanent dental caries, caries in the primary and/or permanent dentitions, number of decayed/missing/ filled first permanent molars in the study and control groups, the distribution in low and elevated caries risk groups, respectively, when entering the study

\begin{tabular}{|c|c|c|c|c|c|}
\hline & \multicolumn{2}{|c|}{$\begin{array}{l}\text { Study group } \\
\mathrm{n}(\%)\end{array}$} & \multicolumn{2}{|c|}{$\begin{array}{l}\text { Control group } \\
\mathrm{n}(\%)\end{array}$} & $\begin{array}{l}\text { Total } \\
\mathrm{n}(\%)\end{array}$ \\
\hline \multicolumn{6}{|l|}{ Caries } \\
\hline \multicolumn{6}{|l|}{ Caries in primary teeth } \\
\hline $\mathrm{deft}=0$ & \multicolumn{2}{|c|}{$137(70.6)$} & \multicolumn{2}{|c|}{$108(77.7)$} & $245(73.6)$ \\
\hline $\operatorname{deft}>0$ & \multicolumn{2}{|c|}{$57(29.4)$} & \multicolumn{2}{|c|}{$31(22.3)$} & $88(26.4)$ \\
\hline \multicolumn{6}{|l|}{ Caries in permanent teeth } \\
\hline $\mathrm{DMFT}=0$ & \multicolumn{2}{|c|}{$130(76.0)$} & \multicolumn{2}{|c|}{$102(73.4)$} & $232(69.7)$ \\
\hline $\mathrm{DMFT}>0$ & \multicolumn{2}{|c|}{$64(33.0)$} & \multicolumn{2}{|c|}{$37(26.6)$} & $101(30.3)$ \\
\hline \multicolumn{6}{|c|}{ Caries in primary and/or permanent dentition } \\
\hline deft and DMFT $=0$ & \multicolumn{2}{|c|}{$96(49.5)$} & \multicolumn{2}{|c|}{$82(59.0)$} & $178(53.5)$ \\
\hline deft and DMFT $>0$ & \multicolumn{2}{|c|}{$98(50.5)$} & \multicolumn{2}{|c|}{$57(41.0)$} & $155(46.5)$ \\
\hline \multicolumn{6}{|c|}{ Number of decayed/missing/filled first permanent molars } \\
\hline $\mathrm{DMFT}=0$ & \multicolumn{2}{|c|}{$138(71.1)$} & \multicolumn{2}{|c|}{$113(81.3)$} & $251(75.4)$ \\
\hline DMFT $>0$ & \multicolumn{2}{|c|}{$56(28.9)$} & \multicolumn{2}{|c|}{$26(18.7)$} & $82(24.6)$ \\
\hline \multicolumn{6}{|c|}{ Number of decayed/missing/filled first permanent molars including initial caries } \\
\hline $\mathrm{DMFTi}=0$ & \multicolumn{2}{|c|}{$111(57.2)$} & \multicolumn{2}{|c|}{$93(66.9)$} & $204(61.3)$ \\
\hline DMFTi $>0$ & \multicolumn{2}{|c|}{$83(42.8)$} & \multicolumn{2}{|c|}{$46(33.1)$} & $129(38.7)$ \\
\hline \multicolumn{6}{|l|}{ Caries risk assessment } \\
\hline Low risk & \multicolumn{2}{|c|}{$138(71.1)$} & \multicolumn{2}{|c|}{$114(82.0)$} & $252(75.7)$ \\
\hline \multirow[t]{2}{*}{ Elevated risk } & \multicolumn{2}{|c|}{$56(28.9)$} & & & $81(24.3)$ \\
\hline & $\mathrm{n}$ & OR & $\mathrm{CI}$ & $\mathrm{p} \log$ reg & $\mathrm{p} \log$ reg B-H \\
\hline Caries in primary teeth & 333 & 1.45 & $0.88-2.42$ & n.s & n.s \\
\hline Caries in permanent teeth & 333 & 1.35 & $0.82-2.22$ & n.s & n.s \\
\hline Caries prim and/or perm dent & 333 & 1.46 & $0.94-2.28$ & n.s & n.s \\
\hline DMFT & 333 & 1.78 & $1.04-3.09$ & 0.038 & n.s \\
\hline DMFTi & 333 & 1.51 & $0.95-2.43$ & n.s & n.s \\
\hline Caries risk assessment & 333 & 2.42 & $0.98-6.86$ & n.s & n.s \\
\hline
\end{tabular}

Percentage within brackets (Deft decayed/extracted/filled primary teeth, DMFT decayed/missing/filled first permanent molars, DMFTi decayed/ missing/filled first permanent molars and initial caries)

The lower part of the table shows the results from the logistic regression [ $n$ number, n.s. non-significant, $O R$ odds ratio, CI confidence interval (95\%), p log reg p-value logistic regression, p log reg $B-H$ p-value logistic regression with Bonferroni-Holm correction]

$(p=0.038)$, however, after Bonferroni-Holm correction (BH-c), the difference was not significant. The OR for DMFT $>0$ was 1.78 (Table 1).

\section{Caries risk assessment (R2)}

In the study group, $28.9 \%$ of the children had an elevated caries risk, compared to $18 \%$ in the control group, and the difference was not statistically significant. The OR for elevated caries risk was 2.42 (Table 1).

\section{Oral health behaviour}

\section{Tooth brushing}

More children with externalising behaviour brushed their teeth less than twice a day, and when compared to the controls, the difference was statistically significant $(p=0.0007$ after BH-c $p=0.01$ ) (Table 2). The OR for tooth brushing less than twice a day was 2.80 .

\section{Drinking when thirsty}

Children with externalising behaviour preferred drinks other than water or milk, more often when thirsty, 
Table 2 The upper part of the table shows the frequencies of the risk factors connected to oral health behaviour in children with externalising behaviour problems compared to controls

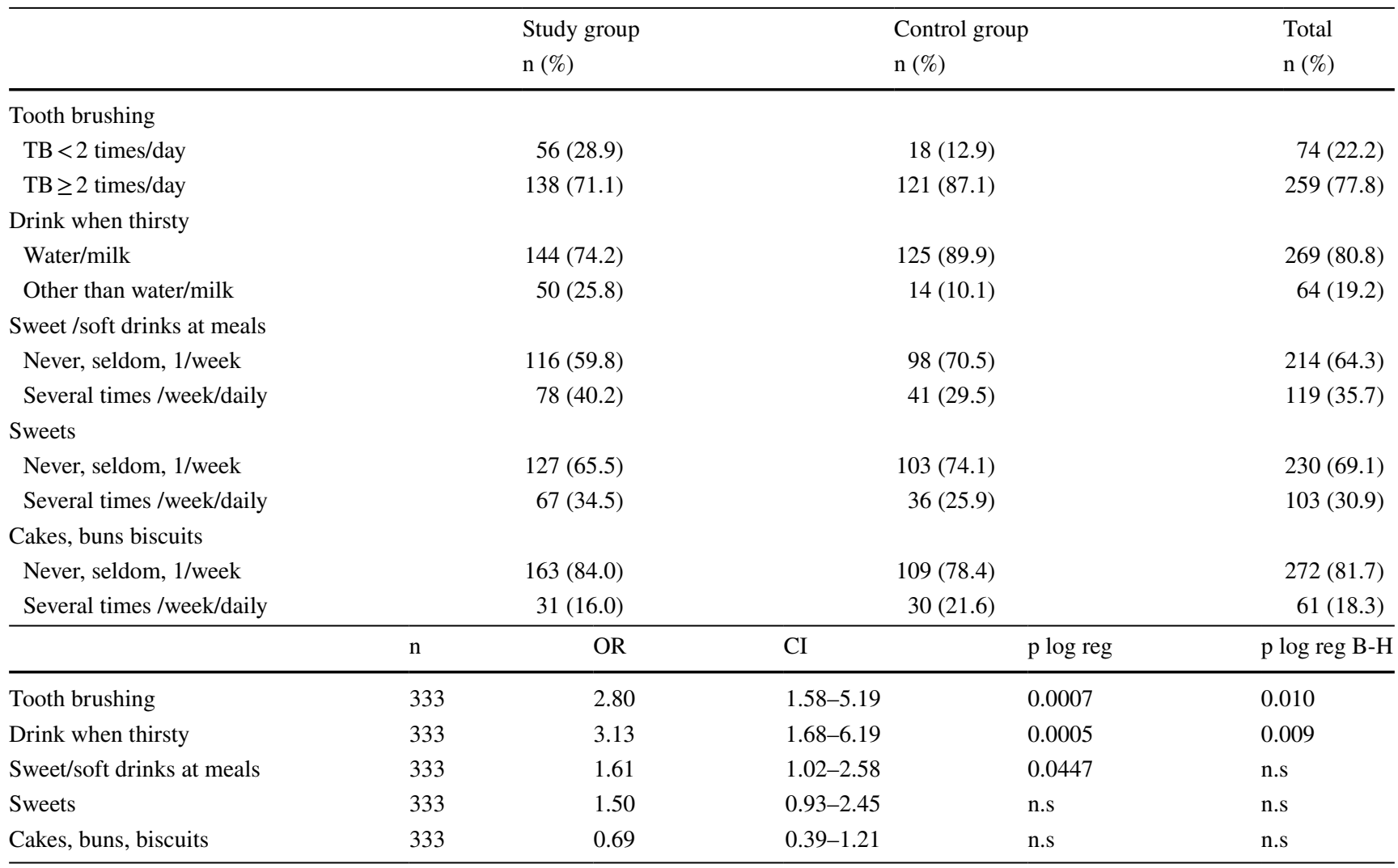

Percentage within brackets

The lower part of the table shows the results from the logistic regression [ $n$ number, n.s. non-significant, $O R$ odds ratio, $C I$ confidence interval (95\%), p log reg p-value logistic regression, p log reg $B-H$ p-value logistic regression with Bonferroni-Holm correction]

compared to the controls. The logistic regression analysis showed a statistically significant difference $(p=0.0005$; after BH-c $p=0.009$ ) (Table 2). The OR for preferring other beverages than water or milk when thirsty was 3.13.

\section{Sweet/soft drinks at meals}

In the study group, $40.2 \%$ of the children frequently (several times/week/daily) drank sweetened drinks at meals, compared to $29.5 \%$ in the control group, however, the difference was not statistically significant. The OR for drinking sweetened/soft drinks at meals several times a week/ daily was 1.62 (Table 2).

\section{Sweets}

Children with externalising behaviour more often consumed sweets several times per week or daily compared to the controls ( 34.5 vs. $25.9 \%$ ), but the difference was not statistically significant. The OR for consuming sweets several times /week/daily was 1.50 (Table 2).

\section{Cakes, buns, biscuits}

No differences were found regarding the consumption of cakes, buns and biscuits between the two groups (Table 2). 
Table 3 The upper part of the table shows the frequencies of traumatic dental injuries (TDI) in the primary and permanent dentitions in children with externalising behaviour problems compared to controls

\begin{tabular}{|c|c|c|c|c|c|}
\hline & $\begin{array}{l}\text { Stud } \\
\mathrm{n}(\%\end{array}$ & & \multicolumn{2}{|c|}{$\begin{array}{l}\text { Control group } \\
\mathrm{n}(\%)\end{array}$} & $\begin{array}{l}\text { Total } \\
\mathrm{n}(\%)\end{array}$ \\
\hline \multicolumn{6}{|l|}{ TDI both dentitions } \\
\hline No TDI & \multicolumn{2}{|c|}{$94(48.5)$} & \multicolumn{2}{|c|}{$97(69.8)$} & $191(57.4)$ \\
\hline TDI & \multicolumn{2}{|c|}{$100(51.5)$} & \multicolumn{2}{|c|}{$42(30.2)$} & $142(42.6)$ \\
\hline \multicolumn{6}{|l|}{ TDI primary dentition } \\
\hline No TDI & \multicolumn{2}{|c|}{$132(68.0)$} & \multicolumn{2}{|c|}{$116(83.5)$} & $248(74.5)$ \\
\hline TDI & \multicolumn{2}{|c|}{$62(32.0)$} & \multicolumn{2}{|c|}{$23(16.5)$} & $85(25.5)$ \\
\hline \multicolumn{6}{|l|}{ TDI permanent dentition } \\
\hline No TDI & \multicolumn{2}{|c|}{$134(69.1)$} & \multicolumn{2}{|c|}{$114(82.0)$} & $248(74.5)$ \\
\hline \multirow[t]{2}{*}{ TDI } & \multicolumn{2}{|c|}{$60(30.9)$} & \multicolumn{2}{|c|}{$25(18.0)$} & $85(25.5)$ \\
\hline & $\mathrm{n}$ & OR & CI & $\mathrm{p} \log$ reg & $\mathrm{p} \log$ reg B-H \\
\hline TDI both dentitions & 333 & 2.47 & $1.57-3.93$ & 0.0001 & 0.002 \\
\hline TDI primary dentition & 333 & 2.42 & $1.42-4.22$ & 0.0014 & 0.020 \\
\hline TDI permanent dentition & 333 & 2.04 & $1.21-3.52$ & 0.0082 & n.s \\
\hline
\end{tabular}

Percentage within brackets

The lower part of the table shows the results from the logistic regression [ $n$ number, n.s. non-significant, $O R$ odds ratio, CI confidence interval (95\%), p log reg p-value logistic regression, p log reg $B-H$ p-value logistic regression with Bonferroni-Holm correction]

\section{Traumatic dental injuries}

There were more children with externalising behaviour who had traumatic dental injuries (TDI) in both dentitions, compared to the controls (51.5 and $30.2 \%$, respectively). The logistic regression showed a statistically significant difference ( $p<0.0001$; after BH-c $p=0.002$; OR 2.47) (Table 3).

TDI in the primary dentition was statistically significantly more common among the externalising children, compared to the controls (32 vs. $16.5 \%, p=0.0014$; after BH-c $p<0.02$; OR 2.42). In the permanent dentition, TDI was significantly more common among the externalising children (30.9 vs. $18 \% ; p=0.008$; OR 2.04), however, the difference was nonsignificant after BH-c (Table 3).

\section{Behaviour management problems (BMP)}

The frequency of BMP was $10.3 \%$ in the study group and $2.2 \%$ in the control group, and the difference was statistically significant $(p<0.009$; after BH-c non-significant; OR 5.25).

\section{Risk for dental fear (CFSS-DS)}

There were 10 children in the study group with dental fear (CFSS-DS $\geq 38$ ), however, none in the control group reached a value of CFSS-DS $\geq 38$. The mean value for the CFSS-DS score in the study group was 24.07 (SD 7.403), and in the control group 20.16 (SD 4.677).
In the study group and the control group, $15.5 \%$ and $2.2 \%$ of the children had a CFSS-DS value $\geq 32$, respectively, and were thus classified as having a higher risk for dental fear. The difference was statistically significant $(p=0.0005$; after BH-c $p=0.009$; OR 8.61). No correlation was found between risk for dental fear and TDI.

\section{Parental evaluation of dental care and dental health}

There was no statistical difference between children with externalising behaviour problems, compared to controls, regarding the parent's evaluation of their child's dental health. The OR value was 2.34 (Table 4). There were more parents in the study group evaluating the dental care as poor or not functioning ( $p=0.03$; after BH-c non-significant; OR 4.05) (Table 4).

\section{Discussion}

This study has shown that the caries prevalence was not higher in children with early-detected externalising behaviour problems, compared to the controls. However, it was more common that these children brushed their teeth fewer than twice a day, and consumed more sweetened drinks. These individual risk factors might lead to a future increased risk of being in the elevated caries risk group. Furthermore, these children had more dental trauma in both dentitions, and a higher risk range for dental fear, compared to the controls. 
Table 4 The upper part of the table shows the frequencies of behaviour management problems (BMP), risk for dental fear according to Children's Fear Survey Schedule (CFSS-DS) and parental evaluation

\begin{tabular}{|c|c|c|c|c|c|}
\hline & & $\begin{array}{l}\text { Study group } \\
\mathrm{n}(\%)\end{array}$ & \multicolumn{2}{|c|}{$\begin{array}{l}\text { Control group } \\
\mathrm{n}(\%)\end{array}$} & $\begin{array}{l}\text { Total } \\
\mathrm{n}(\%)\end{array}$ \\
\hline \multicolumn{6}{|c|}{ Behaviour management problems } \\
\hline No BMP & & $174(89.7)$ & \multicolumn{2}{|c|}{$136(97.8)$} & $310(93.1)$ \\
\hline BMP & & $20(10.3)$ & \multicolumn{2}{|c|}{$3(2.2)$} & $23(6.9)$ \\
\hline \multicolumn{6}{|l|}{ Risk for dental fear } \\
\hline CFSS-DS $<32 p$ & & $164(84.5)$ & \multicolumn{2}{|c|}{$135(97.1)$} & $299(90.0)$ \\
\hline CFSS-DS $\geq 32 p$ & & $30(15.5)$ & \multicolumn{2}{|c|}{$3(2.2)$} & $33(9.9)$ \\
\hline \multicolumn{6}{|c|}{ Dental health (parental evaluation) } \\
\hline Very good & & $95(52.5)$ & \multicolumn{2}{|c|}{$97(69.8)$} & $192(60.0)$ \\
\hline Good/poor & & $86(47.5)$ & \multicolumn{2}{|c|}{$42(30.2)$} & $128(40.0)$ \\
\hline \multicolumn{6}{|c|}{ Dental care (parental evaluation) } \\
\hline Well-functioning & & $178(91.8)$ & \multicolumn{2}{|c|}{$136(97.8)$} & $314(94.3)$ \\
\hline \multirow[t]{2}{*}{ Poor } & & $16(8.2)$ & \multicolumn{2}{|c|}{$3(2.2)$} & $19(5.7)$ \\
\hline & $\mathrm{n}$ & OR & CI & $\mathrm{p} \log$ reg & $\mathrm{p} \log$ reg B-H \\
\hline BMP & 333 & 5.25 & $1.75-22.63$ & 0.0086 & n.s \\
\hline Risk for dental fear & 332 & 8.61 & $2.96-36.60$ & 0.0005 & 0.0089 \\
\hline \multicolumn{6}{|l|}{ Evaluation by parents } \\
\hline Dental health & 320 & 2.34 & $0.68-10.71$ & n.s & n.s \\
\hline Dental care & 333 & 4.05 & $1.31-17.66$ & 0.0289 & n.s \\
\hline
\end{tabular}

Percentage within brackets

The lower part of the table shows the results from the logistic regression [ $n$ number, n.s. non-significant, $O R$ odds ratio, $C I$ confidence interval (95\%), p log reg p-value logistic regression, $p \log r e g B-H$-value logistic regression with Bonferroni-Holm correction]

A strength of the present study was the selection criteria of including families from different socio-economic areas, and the use of the validated instruments, SDQ and CFSSDS. In this study, the Bonferroni-Holm correction was used, but the unadjusted values are also presented, adding valuable information.

Children with early-detected externalising behaviour problems had fared well in terms of caries. There was no significant difference regarding caries, compared to the controls, which is in accordance with a previous study of young children (aged 3-8 years) (Lorber et al. 2014). In a study of children with ADHD at age 13 years, the caries prevalence was not higher compared to controls (Blomqvist et al. 2007). However, teenagers (aged 17 years) with ADHD had a higher prevalence of caries, compared to the controls (Blomqvist et al. 2011).

The OR value of 2.42 in the caries risk assessment found in the present study indicated a need for special attention regarding caries in children with externalising behaviour. Since the individual risk factors may lead to a higher future caries activity during adolescence, these children should belong to the elevated caries risk group. This study has pointed out potential risk factors in children with earlydetected externalising behaviour problems. This means that of dental care and the child's dental health in children with externalising behaviour problems compared to controls 
of dental trauma in both dentitions, $51.5 \%$, was higher than the $42.9 \%$ found among 11-13-year-old in a previous Swedish study on dental trauma (Oldin et al. 2015). Therefore problem behaviour can be an additional risk factor for traumatic dental injuries (TDI), which is in line with a previous study (Oldin et al. 2015). Furthermore, the children at risk for dental fear, CFSS-DS $\geq 32$, had not been exposed to more dental trauma compared to those without dental trauma.

The children in the study group had to have a value of 3 or more on the SDQ-CD scale to be regarded as having a clinical relevant behaviour problem. Due to the child's impulsivity and conduct problems, this risk for "acting out" behaviour may lead to more arguments with friends and intentional or unintentional injuries.

The child's activities and the environment, e.g., the child's sociability, may be another determining risk factor for TDI, which is in agreement with a recently presented Swedish study (Oldin et al. 2015). Impulsivity and attentionrelated problems, associated with externalising behaviour problems, may influence the child's inhibition systems and limit the child's risk assessment, leading to activities without thinking of consequences and thereby, increasing the risk for dental trauma.

Studies from the UK have established a relationship between emotional disorders and unintentional injuries, where children with disruptive behaviour had an increased risk for injuries, as a result of their hyperactivity and emotionality (Lalloo et al. 2003; Rowe et al. 2004). Due to the trauma risk, interceptive orthodontic treatment in children with externalising behaviour and a large incisal overjet could be a good preventive measure, since the incisal overjet has been shown to be a risk factor for TDI (Forsberg and Tedestam 1993).

A high OR value for behaviour management problems was found among the children with externalising behaviour problems in this study. The connection between BMP and externalising behaviour are in line with earlier findings in a Swedish study (Blomqvist et al. 2004). One factor that can explain the behaviour management problems is the age of the child, since BMP has been shown to decline with age (Klingberg et al. 1994). The BMP could also possibly be explained by the dental team's inexperience of treating externalising children (Staberg et al. 2014a). Dental teams, who are able to develop warm and supportive relationships with these children, have the potential to create a well-functioning and positive dental experience, and reduce the risk for a negative oral health outcome, which has been shown in the present study, where the parents were satisfied with the dental care.

\section{Conclusions}

This study has pointed out potential oral health risk factors in children with early-detected externalising behaviour problems, compared to a matched control group. Although no difference in caries prevalence was observed, externalising behaviour may affect oral health, caries, and dental trauma, and may increase the risk for dental fear. By paying attention to the child's behaviour and listening to the parents during the dental visit, the dental teams may be able to identify externalising children. This means the dental professionals have great opportunities to assist and support the families by offering an increased number of contact times and prophylactic measures. In this way, dental care may preserve the dental health of the children. There were no differences between children with externalising behaviour problems, compared to the controls, regarding the parent's evaluation of their child's dental health. However, in the study group, more parents evaluated the dental care as poor or not functioning.

\section{Clinical implications}

This study has shown that externalising behaviour ought to be added to the repertoire of factors considered for caries risk evaluation. Since the parents evaluated the dental care as poor or not functioning, the dental professionals should consider this fact when treating and planning dental care. Furthermore, externalising children with a large overjet should be offered interceptive orthodontic treatment.

The collaboration in prevention between the Public Dental Service, the school, and the social services, described in this study, is unique for Swedish conditions.

If the regular dental service identifies children with externalising behaviour problems, this could be valuable for their oral health, and in addition, may initiate a contact between the family and the social services for support and help, such as participating in parent management training programmes.

Acknowledgements This study was supported by the region of Västra Götaland, and the Swedish National Board of Health and Welfare.

\section{Compliance with ethical standards}

Conflict of interest The authors declare that there were no conflicts of interest.

Open Access This article is distributed under the terms of the Creative Commons Attribution 4.0 International License (http://creativeco mmons.org/licenses/by/4.0/), which permits unrestricted use, distribution, and reproduction in any medium, provided you give appropriate credit to the original author(s) and the source, provide a link to the Creative Commons license, and indicate if changes were made. 


\section{References}

Aminabadi NA, Najafpour E, Erfanparast L, et al. Oral health status, dental anxiety, and behavior-management problems in children with oppositional defiant disorder. Eur J Oral Sci. 2016;124(1):45-51.

Andas CA, Hakeberg M. Who chooses prepaid dental care? A baseline report of a prospective observational study. BMC Oral Health. 2014; $14: 146$.

Aunger R. Tooth brushing as routine behaviour. Int Dent J. 2007;57(5):364-76.

Avsar A, Akbas S, Ataibis T. Traumatic dental injuries in children with attention deficit/hyperactivity disorder. Dent Traumatol. 2009;25(5):484-9.

Blomqvist M, Holmberg K, Fernell E, Dahllof G. A retrospective study of dental behavior management problems in children with attention and learning problems. Eur J Oral Sci. 2004;112(5):406-11.

Blomqvist M, Holmberg K, Fernell E, Ek U, Dahllof G. Dental caries and oral health behavior in children with attention deficit hyperactivity disorder. Eur J Oral Sci. 2007;115(3):186-91.

Blomqvist M, Ahadi S, Fernell E, Ek U, Dahllof G. Dental caries in adolescents with attention deficit hyperactivity disorder: a population-based follow-up study. Eur J Oral Sci. 2011;119(5):381-5.

Bloomquist ML, Schnell SV. Helping Children with Aggression and Conduct problems: Best practices for intervention. New York: Guilford Press; 2002.

Cuthbert MI, Melamed BG. A screening device: children at risk for dental fears and management problems. ASDC J Dent Child. 1982;49(6):432-6.

Fagerstad A, Lundgren J, Arnrup K. Dental fear among children and adolescents in a multicultural population-a cross-sectional study. Swed Dent J. 2015;39(2):109-20.

Forsberg CM, Tedestam G. Etiological and predisposing factors related to traumatic injuries to permanent teeth. Swed Dent J. 1993;17(5):183-90.

Goodman R. The Strengths and Difficulties Questionnaire: a research note. J Child Psychol Psychiatry. 1997;38(5):581-6.

Goodman R. Psychometric properties of the strengths and difficulties questionnaire. J Am Acad Child Adolesc Psychiatry. 2001;40(11):1337-45.

Herguner A, Erdur AE, Basciftci FA, Herguner S. Attention-deficit/ hyperactivity disorder symptoms in children with traumatic dental injuries. Dent Traumatol. 2015;31(2):140-3.

Klingberg G, Broberg AG. Dental fear/anxiety and dental behaviour management problems in children and adolescents: a review of prevalence and concomitant psychological factors. Int J Paediatr Dent. 2007;17(6):391-406.
Klingberg G, Vannas Lofqvist L, Bjarnason S, Noren JG. Dental behavior management problems in Swedish children. Community Dent Oral Epidemiol. 1994;22(3):201-5.

Lalloo R, Sheiham A, Nazroo JY. Behavioural characteristics and accidents: findings from the Health Survey for England, 1997. Accid Anal Prev. 2003;35(5):661-7.

Loe $\mathrm{H}$. Oral hygiene in the prevention of caries and periodontal disease. Int Dent J. 2000;50(3):129-39.

Lorber MF, Smith Slep AM, Heyman RE, Bretz WA. Child externalising behavior problems linked to genetic and non-genetic variation in dental caries. Caries Res. 2014;48(5):475-81.

Ogundele MO. Behavioural and emotional disorders in childhood: a brief overview for paediatricians. World J Clin Pediatr. 2018;7(1):9-26. https://doi.org/10.5409/wjcp.v7.i1.9.

Oldin A, Lundgren J, Noren JG, Robertson A. Temperamental and socioeconomic factors associated with traumatic dental injuries among children aged 0-17 years in the Swedish BITA study. Dent Traumatol. 2015;31(5):361-7.

Ptacek R, Kuzelova H, Stefano GB, et al. Disruptive patterns of eating behaviors and associated lifestyles in males with ADHD. Med Sci Monit. 2014;20:608-13.

Rowe R, Maughan B, Goodman R. Childhood psychiatric disorder and unintentional injury: findings from a national cohort study. J Pediatr Psychol. 2004;29(2):119-30.

Smedje H, Broman JE, Hetta J, von Knorring AL. Psychometric properties of a Swedish version of the "Strengths and Difficulties Questionnaire". Eur Child Adolesc Psychiatry. 1999;8(2):63-70.

Staberg M, Noren JG, Johnson M, Kopp S, Robertson A. Parental attitudes and experiences of dental care in children and adolescents with ADHD—a questionnaire study. Swed Dent J. 2014a;38(2):93-100.

Staberg M, Noren JG, Johnson MK, Kopp S, Robertson A. Oral health and dental care among children and adolescents with ADHD-a retrospective and exploratory study. 2014b;15(4):5-13.

Staberg M, Noren JG, Gahnberg L, et al. Behavioural characteristics in externalising children with low and elevated risk for caries. Eur Arch Paediatr Dent. 2016. https://doi.org/10.1007/s4036 8-016-0256-6.

ten Berge M, Veerkamp JS, Hoogstraten J, Prins PJ. Childhood dental fear in the Netherlands: prevalence and normative data. Community Dent Oral Epidemiol. 2002;30(2):101-7.

Twetman S, Fontana M, Featherstone JD. Risk assessment-can we achieve consensus? Community Dent Oral Epidemiol. 2013;41:64-70.

Wigen TI, Wang NJ. Does early establishment of favorable oral health behavior influence caries experience at age 5 years? Acta Odontol Scand. 2015;73(3):182-7. 